\title{
Does Male International Migration Effects the Families Left behind Evidence from Gujrat Pakistan
}

\author{
Shahid Iqbal, Faiza Iqbal, Riaz Ahmed Mozmi \\ Department of Anthropology, Quaid-i-Azam University, Islamabad, Pakistan \\ Email: sargana s@yahoo.com, fza.iabal@gmail.com, ch.mozmi@gmail.com
}

Received 18 April 2014; revised 3 June 2014; accepted 17 June 2014

Copyright (C) 2014 by authors and Scientific Research Publishing Inc.

This work is licensed under the Creative Commons Attribution International License (CC BY).

http://creativecommons.org/licenses/by/4.0/

(c) (i) Open Access

\begin{abstract}
Migration has been a courageous expression of the individual's will to overcome adversity and to live a better life. Today, globalization, together with advances in communications and transportation, has greatly increased the number of people who have the desire and the capacity to move to other places. The evidence shows that due to flow of remittances the economic status of the families but on the other hand it also has a profound impact on families left behind. They have to face many problems. In this study, an effort has been made to understand the possible impact of migration on families left behind. This study was carried out in District Gujrat of Punjab Pakistan. Purposed sampling technique has been used to select the sample. The findings of the study suggest that male migration has a profound impact on families left behind especially on their spouse and children.
\end{abstract}

\section{Keywords}

Male Migration, Families Left Behind, Flow of Remittances, Pakistan

\section{Introduction}

International migration has grown progressively in complexity and significance in the global scape. Migration is both a cause and effect of broader development processes and an intrinsic feature of our ever globalizing world. Giants in the development world such as the United Nations are treating migration as "a positive force for development". The lure to migrate from developing to developed countries mainly lies in the hope of gaining access to better economic opportunity. According to a World Bank report, 175 million people, or 3 percent of the world's population, lived outside their country of birth in 2000 [1]. However, academic interest in the pheno- 
menon has revealed that “international migration” can have a multitude of consequences for sending countries as well as receiving areas.

\subsection{Migration Trends in Pakistan}

Migration is particularly important in developing countries like Pakistan where it is an important social practice and economic factor. The urge to migrate originates from one's desire to escape poverty. This is particularly true for people living in small settlements with relatively fewer resources. About four million labor migrants live outside Pakistan, half of them in the six countries of the Gulf Cooperation Council [2]. The 1973 oil crisis and the subsequent boom in the Gulf region opened new opportunities for large numbers of Pakistanis to work in the Middle East on short-term contracts [3]-[5]. Most of this migrant force comprises of men rather than women migrants [6]. Both the policy makers and the analyst have welcomed the effects of these migrations and the consequent remittance flow on the economy [7] [8]. A study of villages affected by the major earthquake that shook Pakistan in 2005, indeed demonstrate that international labor migration constituted an enabling factor for strengthening remittance receiving households' resilience [9].

Gulf migration from Pakistan is unevenly across the country. Rural regions of low agricultural productivity, such as the rain-fed areas of the North-West Frontier Province (NWFP), are the main sources semi-skilled migrant workers [10]. Resultantly, of all provinces, rural KPK is most dependent on foreign remittances. About a tenth of average monthly incomes consist of remittance flows.

However while these migrations are a cause of financial stability and a means to bring foreign exchange to the country's economy, it has also set in motion social change on the family front.

\subsection{The Effect of Migration on Families}

Migration provide opportunity for individuals to earn significantly higher incomes to the benefit of all family members, it is also often accompanied by long-term family separations [11]. As a major family decision, migration by a family member may have complicated direct and indirect effects on the lives of children and on the family in general. This may take many forms, whether it is an entire nuclear family separating from extended family in the source country or a parent or child migrating alone with dependents left behind. In many parts of the world, this type of migration is circular and recurrent, raising questions about the impact of migration on family members left behind and their reliance on the migrant for support.

\subsection{Pathways through Which Parental Migration Influences Child Development}

Albert Park, Leng Lee, and Alan deBrauw mention certain pathways to consider when reviewing the impact of parental migration on child development in their recent article [11]. The first effect as stated by them is a positive one, associated with higher incomes, which is typically the main motivation for migration. International migration is associated with very high income increases [12]. Greater family resources mean greater investment on children e.g. education and health. A strong link has been acknowledged between higher household incomes and a variety of child development outcomes [13] [14].

The second is a negative effect due to the lack of parental contact with children. The effect this separation from one or both parents may differ according to the situation the children are in. A difference may also been seen in children whose mothers are away as compared to those having their fathers abroad. The presence and capabilities of substitute caretakers is also an important factor. Psychological research has found that parental support is a significant predictor of student's capacity to deal with stress, anxiety and loss of control [15]. Children with strong parental support do better in school and develop mature psychological traits. They aspire to do good work, experience pleasure in one's work, and develop both initiative and a sense of control over events, and are better behaved [16]. Environments that destabilize a child's sense of self control over their life may increase the likelihood of internalizing problems [17].

This research focuses on father absence in particular, which is usually negatively associated with a variety of child level outcomes in developed countries [18].

Children who live in single mother families have been found to have lower academic achievement scores and are more likely to drop out of school [19] [20]. Children living with their mothers are also more likely to suffer from psychological or behavioral problems. However, research has also shown that among children with non-resident fathers, the frequency of contact has little effect on child outcomes but the closeness of the relationship 
may still be important [21].

A third factor is stated as effects on the "labor supply decisions of other household members" due to one or more persons such caused absence. For example, if men migrate women may be required to spend more time looking after all aspects of the family's need, reducing time available to spend with children. Or children themselves could be expected to do more work. The main point is that household time allocation decisions are interdependent and influenced by migration, and how both parents and children spend their time critically impacts a child's development.

A fourth channel is the impact of migration on parental information and/or attitudes. For instance, greater exposure to the outside world could alter beliefs about the returns to human capital investments in children. Or parents could learn more about the importance of child health or gain knowledge about how to promote children's health [11].

A fifth impact of parental migration is that it may increase the probability of future migration by children. This can occur through better job information and job search networks that migrant parents can provide to the child, or through a role model effect. Recent theoretical work also argues that there can be a "brain gain" whereby migration has an additional positive impact on education in the source economy; with increased returns to schooling, there are greater incentives to accumulate more education [22].

A sixth factor influencing children is the impact of migration on household decision making authority. If one parent is absent, the other may gain greater control over decisions affecting the child (especially through household spending decisions), which can be important when the preferences or views of the two parents differ. Given these different pathways of influence, the impacts of parental migration on children are likely to depend on many intermediating factors such as the duration of migration, the amount of remittances sent back, the age and gender of both child and parent, the size and composition of the household and its relatives, and the size and nature of village migration [11].

\subsection{Impact on Spouse}

Nichols observes that "gender relations were increasingly adjusted or upset as women left behind by migrating husbands took charge of family affairs and finances” [23]. However, when it comes to Pakistan, very little researches have addressed the gender dimension of families left behind by migrants. In its wider scope a researcher may find more work done on migrating women than those left behind. Of the works which do pertain to the topic at hand, we find two themes running through this literature; women's greater workload associated with male emigration and women's participation in traditionally male social and economic spheres may increase over and above their tasks in the domestic sphere [24] [25]. Associated with the greater involvement in traditionally male tasks, women may gain more control. They may become de facto heads of household. The meanings attributed to these reorganized material and symbolic borders that delineate femininity and masculinity.

Some scholars like Jolly and Reeves remark that this shift in women's role is directly linked to the practice of greater economic independence, which in turn ensue greater confidence and relatively more freedom in action [24]. There are others who treat this increased "power to decide" is but a step towards yet to be realized "women's greater empowerment”.

Furthermore Lefebvre identifies a reinforcement of women's seclusion by their male household members' migration to the Middle East as an external sign of one's social upgrading. Lefebvre observes contradictory processes of change going on simultaneously. Whereas female seclusion uncommon in her research site before is also beginning to take place, some women are becoming more outward going with the financial and moral support of their migrating men-folk [26].

\subsection{Objectives of the Study}

- To know about the socio economic status of the households.

- To unearth the impact male migration (if any) on their children left behind.

- To measure the possible impact of male migration on females left behind.

- To know about the possible effect of male migration at household.

\section{Methodology}

A qualitative technique was used to gather and interpret the data and the findings of the study are mainly based 
on the empirical data. The researcher used interview schedule, direct observation and content analysis methods for the collection and analysis of the data. The respondents of the study were those females who were residual of District Gujrat Pakistan and their husbands were overseas migrated.

Both secondary and primary data were used in the study. In addressing the primary objective of the study, 20 females were selected through convenient, networking and purposive sampling techniques which were used due because the sample frame was not available to the researcher. All the interviews were conducted in Urdu and were translated in to English. The authors had successfully used the similar techniques in other studies [27].

\section{Findings and Discussion}

\subsection{Impact on Children Left Behind}

Male migration has very significant impact on the children left behind. The findings of the study show that children have to face a lot of risk in the absence of their fathers. The main effected dimensions of the children in the absence of their fathers are.

\subsubsection{Education}

It is now well accepted that international migration of a parent or family member has both positive and negative effects on non-migrant children in the home country. First, there is the possibility that remittances sent from abroad will relax the household budget constraint and result in an increase in child schooling, child health, and a corresponding decrease in child labor.

Several studies find evidence supporting this finding [28] [29]. Yet researchers have also recognized that parental migration inherently involves parental absence from the home that can have a negative impact on child outcomes which may outweigh the positive effect of remittances. The situation in Mansera offered a more positive side of the picture. Though the children here reported to miss the migrant parent, but the increase in income meant better quality education in private schools and the facility of computers and internet at home to increase the resourcefulness and motivation of the school going children.

\subsubsection{Discipline}

Zoller Booth [30] stresses the importance of a father's role as disciplinarian and figurehead when interpreting the detrimental effects of paternal labor migration on the school readiness of children in Swaziland. Much like Booth's research, the study at hand also revealed that the important of a father in maintaining discipline in the house. With fathers settled abroad children reacted differently to the new situation discipline wise. Variables include age, gender, birth order, and frequency of father's visits back home and the hold of the mother over the children.

Younger, non-school going children tend to give mothers a harder time as compared to older ones who understood the dynamics of the situation and thus coped with it better. Boys tended to not listen to their mothers more often than girls in the absence of their fathers. Youngest and oldest children in a household took the most time adjusting to the new family dynamics. Similarly children whose fathers visited them more often-about 6 months to 1 year and households where the mothers had assumed the role of the disciplinarian was better behaved.

\subsubsection{Health}

Those Households which had men working abroad generally enjoyed better health than before. All the responding members of households, even those where men were working as laborers in the migrated country, reported of going to private or military hospitals for health treatment. Very few admitted to going to government hospitals that too in only in the rare instance of when the patient needed to be admitted in the hospital. Furthermore health issues were generally tended to on time and effectively. These households mostly relied on allopathic medicine.

\subsubsection{Father Substitution}

It was interesting to see that in most households, the children adjusted to the absence of their father by attaching their feelings with an alternate father figure in the household. This may be the grandfather, uncle, an elder cousin living in the household or in case of elder sons-the assuming of the role of household head themselves. In 
cases where the sons were observed to growing into their fathers shoes-this happened with or without the mother's consent. The son in such situations would assume the duties previously held by the father including that of maintaining discipline, ensuring mothers and sisters' protection, all work outside the premises of the household and male socialization. In instances where mothers did not agree with this change of role of the sons, friction was observed between the two.

\subsection{Impact on Spouse Left Behind}

Migration has profound impact on females left behind. These female may be mothers, sisters, daughters or wives. They impact of migration varies from female to female depending upon the social category of female and family size to which they belong. The more serious impact is when the migrant has no job in abroad is unable to send remittances.

\subsubsection{Decision Making Role}

As the men leave a void in the wake of their absence, this void in mostly filled by either a male member who is already a part of the household (father in law, brother in law, etc.) in terms of decision making authority or seldom by the wives. In situations where the wives assume these responsibilities, decisions pertaining to major life decisions of the children such as their marriage and education are still held by the fathers or at the very least shared. The woman has full authority in decisions of smaller consequences though.

\subsubsection{Relationship with the Children}

In the absence of the father, the mothers had to step in as the disciplinarians in most cases changing their relationship with their children. The children reported that they received more scolding from the mothers than the fathers with whom they enjoyed an indulgent relationship. Consequently most of the children reported to be more scared of their mothers than the fathers. Often times children were reported to resorting to hiding behind fathers to escape from the mothers chidings.

\subsection{Impact of Household}

Many different residence patterns emerge in the absence of the migrating fathers from the house. In some instances it becomes a matrilocal household where the de facto household head is the mother with occasional visits from the father. In joint family systems, the new forms may be varied such as nuclear family of the migrant living with his parent(s), or with his brothers and their families. In a few cases where the nuclear families live alone with one parent (mother), the family "adopted" other male relatives (essentially a mahram for the mother) for their support.

\section{Conclusions}

One of the key issues in any migration study relates to what happens to the family members of the migrants after his migration. Invariably most of the migrants are males who move alone without taking with them their wives and children and other family members. There are several reasons for leaving them behind ranging from not having a family visa to education of children preventing the male migrant's from taking their family members with them.

The impact migration on the women can be positive, negative or both depending on the ability and background, as well as the family environment in which they are placed. Among the adverse consequences of migration loneliness is by far the leading problem, followed by added responsibilities, indebtedness owing to loans raised at the time of emigration, inadequate financial returns from emigration and anxiety. When they enjoy all the fruits of migration, the findings of the study lead to a conclusion that the left behind wives and children of the migrants face several problems too. Majority of left behind wives are in their adulthood, a stage in the life span of a human being which has several developmental tasks like settling down in their lives, managing the family, parenting children, looking after elder etc. having a helping hand from the spouse is always a support to a woman to cope up with such stressful situations. Absence of such a help may add to their burden which leads them to develop different psychological and psychosomatic problems.

The most alarming issue is the emotional and psychological strain that most of women underwent in the ab- 
sence of their husbands. The long time separation added to the inadequate communication between the partners complicated the situation. According to the findings of the study most of the females suffer from many psychological problems like isolation, depression, feeling unwanted, inability to adjust with others, restlessness, lack of confidence, feeling becoming dependent, feeling of loss of family life in the absence of their husbands at home.

Furthermore it was observed that difficulties with children were experience with young mothers. It is evident from the findings children education is affected due to the absence of father. The effect of father's absence is clearer on the male children education.

In future researches should focus more on how migration affects spouses and partners. In particular, the effects of migration on intra-household bargaining power and outcomes reflecting relationship quality with the spouse should be further explored. Researchers should also continue to expand the set of countries and settings under examination. Another important avenue for further research in this area should involve isolating mechanisms hinted at in prior research. To date, most studies continue to focus on estimation of an overall or net effect of migration on outcomes, rather than decomposing the effects to understand the underlying mechanisms. In part, this is due to data limitations which generally do not allow researchers to disentangle and quantify the multitude of effects coinciding with a migration episode. Thus, new and more detailed data sources should be developed to aid in this effort.

\section{References}

[1] United Nations Department of Economic and Social Affairs, Population Division (2011) Trends in International Migrant Stock: Migrants by Age and Sex.

[2] Government of Pakistan (2007) Household Integrated Economic Survey (HIES) 2005-06. Federal Bureau of Statistics, Government of Pakistan, Islamabad.

[3] Addleton, J. (1984) The Impact of International Migration on Economic Development in Pakistan. Asian Survey, 24, 574-596. http://dx.doi.org/10.2307/2644414

[4] Arif, G.M. and Irfan, M. (1997) Population Mobility across the Pakistani Border: Fifty Year Experience. Pakistan Development Review, 36, 989-1005.

[5] Gazdar, H. (2003) A Review of Migration Issues in Pakistan. Regional Conference on Migration, Development and Pro-Poor Policy Choices in Asia, Dhaka, 22-24 June 2003.

[6] Noman, O. (1991) The Impact of Migration on Pakistan's Economy and Society. In: Donnan, Hastings and Werbner Pnina, Eds., Economy and Culture in Pakistan: Migrants and Cities in a Muslim Society, Macmillan Academic and Professional, 77-96.

[7] Ellis, F. (2003) A Livelihoods Approach to Migration and Poverty Reduction. Norwich: Department for International Development (DFID).

[8] Katz, E. and Stark, O. (1986) Labor Migration and Risk Aversion in Less Developed Countries. Journal of Labor Economics, 4, 134-149.

[9] Suleri, A.Q. and Savage, K. (2006) Remittance Increases: A Case Study from Pakistan. London: Overseas Development Institute.

[10] Stillman, S., John, G. and David, M. (2012) The Impact of Migration on Child Health: Experimental Evidence from a Migration Lottery Program. Economic Inquiry, 50, 62-81. http://dx.doi.org/10.1111/j.1465-7295.2009.00284.x

[11] Albert, P., Leng, L. and de Brauw, A. (2010) Parental Migration and Child Well-Being in Developing Countries.

[12] McKenzie, D., John, G. and Steven, S. (2007) Moving to Opportunity, Leaving Behind What? Evaluating the Initial Effects of a Migration Policy on Incomes and Poverty in Source Areas. New Zealand Economic Papers, 41, 197-224. http://dx.doi.org/10.1080/00779950709558509

[13] Blau, D.M. (1999) The Effect of Income on Child Development. Review of Economics and Statistics, 81, $261-276$. http://dx.doi.org/10.1162/003465399558067

[14] Duncan, G.J., Brooks-Gunn, J. and Klebanov, P.K. (1994) Economic Deprivation and Early Childhood Development. Child Development, 65, 296-318. http://dx.doi.org/10.2307/1131385

[15] Demaray, M.K., Malecki, C.K., Davidson, L.M., Hodgson, K.K. and Rebus, P.J. (2005) The Relationship between Social Support and Student Adjustment: A Longitudinal Analysis. Psychology in the Schools, 42, 691-706. http://dx.doi.org/10.1002/pits.20120

[16] Dubow, E.F., Tisak, J., Causey, D., Hryshko, A. and Reid, G. (1991) A Two-Year Longitudinal Study of Stressful Life Events, Social Support, and Social Problem-Solving Skills: Contributions to Children's Behavioral and Academic Adjustment. Child Development, 62, 583-599. http://dx.doi.org/10.2307/1131133 
[17] Chorpita, B.F. and Barlow, D.H. (1998) The Development of Anxiety: The Role of Control in the Early Environment. Psychological Bulletin, 124, 3-21. http://dx.doi.org/10.1037/0033-2909.124.1.3

[18] Single-Rushton, W. and Sara, M. (2002) The Living Arrangements of New Unmarried Mothers. Demography, 39, 415433. http://dx.doi.org/10.1353/dem.2002.0032

[19] Entwisle, D.R. and Alexander, K.L. (1996) Family Type and Children’s Growth in Reading and Math over the Primary Grades. Journal of Marriage and the Family, 58, 341-355. http://dx.doi.org/10.2307/353500

[20] Manski, C.F., Sandefur, G.D., McLanahan, S. and Powers, D. (1992) Alternative Estimates of the Effect of Family Structure during Adolescence on High School Graduation. Journal of the American Statistical Association, 87, 25-37. http://dx.doi.org/10.1080/01621459.1992.10475171

[21] Seltzer, J.A. (1994) Consequences of Marital Dissolution for Children. Annual Review of Sociology, 20, 235-266. http://dx.doi.org/10.1146/annurev.so.20.080194.001315

[22] Mountford, A. (1997) Can a Brain Drain Be Good for Growth in the Source Economy? Journal of Development Economics, 53, 287. http://dx.doi.org/10.1016/S0304-3878(97)00021-7

[23] Nichols, R. (2008) A History of Pashtun Migration, 1775-2006. Oxford University Press, Oxford.

[24] Croll, E.J. and Ping, H. (1997) Migration for and against Agriculture in Eight Chinese Villages. The China Quarterly, 149, 128-146. http://dx.doi.org/10.1017/S0305741000043666

[25] Jolly, S., Bell, E. and Narayanaswamy, L. (2003) Gender and Migration in Asia: Overview and Annotated Bibliography. Institute of Development Studies, Brighton.

[26] Lefebvre, A. (1990) International Labor Migration from Two Pakistani Villages with Different Forms of Agriculture. Pakistan Development Review, 29, 59-89.

[27] Iqbal, S., Idrees and Mohyuddin, A. (2014) Male Migration: Decision Making Autonomy and Changing Roles among Females Left Behind: A Feminist Approach. World Applied Sciences Journal, 29, 480-485.

[28] Alcaraz, C., Daniel, C. and Alejandrina, S. (2012) Remittances, Schooling, and Child Labor in Mexico. Journal of Development Economics, 97, 156-165. http://dx.doi.org/10.1016/j.jdeveco.2010.11.004

[29] Cox-Edwards, Alejandra and Manuelita, U. (2003) International Migration, Remittances and Schooling: Evidence from El Salvador. Journal of Development Economics, 72, 429-461. http://dx.doi.org/10.1016/S0304-3878(03)00115-9

[30] Zoller, B. and Margaret (1995) Children of Migrant Fathers: The Effects of Father Absence on Swazi Children’s Preparedness for School. Comparative Education Review, 39, 195. http://dx.doi.org/10.1086/447307 